\title{
DYNAMIC LOADING, MATRIX MAINTENANCE AND CELL INJECTION THERAPY OF HUMAN INTERVERTEBRAL DISCS CULTURED IN A BIOREACTOR
}

\author{
D.H. Rosenzweig ${ }^{1,2,}$, R. Gawri ${ }^{1, \$}$, J. Moir ${ }^{1}$, L. Beckman ${ }^{1}$, D. Eglin ${ }^{3}$, T. Steffen ${ }^{1,2}$, P.J. Roughley ${ }^{4}$, J.A. Ouellet ${ }^{2}$ \\ and L. Haglund ${ }^{1,2, *}$
}
${ }^{1}$ Orthopaedic Research Laboratory, Division of Orthopaedic Surgery, McGill University, Montreal, Canada
${ }^{2} \mathrm{McGill}$ Scoliosis and Spine Research Group
${ }^{3}$ AO Research Institute Davos, Davos, Switzerland
${ }^{4}$ Shriners Hospital for Children, Montreal, Canada
$\S$ contributed equally

\begin{abstract}
Low back pain originating from intervertebral disc (IVD) degeneration affects the quality of life for millions of people, and it is a major contributor to global healthcare costs. Long-term culture of intact IVDs is necessary to develop ex vivo models of human IVD degeneration and repair, where the relationship between mechanobiology, disc matrix composition and metabolism can be better understood. A bioreactor was developed that facilitates culture of intact human IVDs in a controlled, dynamically loaded environment. Tissue integrity and cell viability was evaluated under 3 different loading conditions: low 0.1-0.3, medium 0.1-0.6 and high 0.1-1.2 MPa. Cell viability was maintained $>80 \%$ throughout the disc at low and medium loads, whereas it dropped to approximately $70 \%$ (NP) and $50 \%$ (AF) under high loads. Although cell viability was affected at high loads, there was no evidence of sGAG loss, changes in newly synthesised collagen type II or chondroadherin fragmentation. Sulphated GAG content remained at a stable level of approximately $50 \mu \mathrm{g} \mathrm{sGAG} /$ $\mathrm{mg}$ tissue in all loading protocols. To evaluate the feasibility of tissue repair strategies with cell supplementation, human NP cells were transplanted into discs within a thermoreversible hyaluronan hydrogel. The discs were loaded under medium loads, and the injected cells remained largely localised to the NP region. This study demonstrates the feasibility of culturing human IVDs for 14 days under cyclic dynamic loading conditions. The system allows the determination a safe range-of-loading and presents a platform to evaluate cell therapies and help to elucidate the effect of load following cell-based therapies.
\end{abstract}

Keywords: Intervertebral discs, organ culture, dynamic loading, cell therapy, bioreactor, hydrogel, tissue regeneration.

*Address for correspondence:

Lisbet Haglund,

McGill University Health Centre,

Department of Surgery,

Montreal General Hospital, Room C10 148.2,

1650 Cedar Ave, Montreal, QC H3G 1A4,

Telephone number: (514) 9341934 ext. 35380,

E-mail: lisbet.haglund@mcgill.ca

\section{Introduction}

Intervertebral discs (IVDs) are the soft, largely avascular tissues found between vertebral bodies of motion segments in the spine. The main function of IVDs is to allow for bending, twisting and load-bearing along the spinal column (Humzah et al., 1988). IVD tissue is comprised of the inner gelatinous nucleus pulposus (NP), the outer fibro-cartilaginous annulus fibrosus (AF) and the upper and lower cartilage endplates. The cartilage endplates, $\mathrm{NP}$ and AF each contain region-specific cells, which are responsible for tissue maintenance. NP tissue is highly hydrated and proteoglycan-rich, providing hydrostatic resistance to compression (Nachemson, 1960). The AF contains less proteoglycan and is arranged in concentric lamellar rings rich in collagen type I, thereby providing resistance to tensile strain (Marchand et al., 1990). The cartilage endplates allow for diffusion of nutrient and waste into and out of the disc via the vasculature within the vertebral bone (Holm et al., 1981). IVD degeneration is an incompletely understood process where this tissue loses proteoglycan and water content, and increases production of inflammatory factors and catabolic proteases, ultimately leading to mechanical failure and loss of tissue function (Adams et al., 2006).

IVD degeneration is thought to be a direct cause of low back pain (Adams et al., 2015; Adams et al., 2006), a condition affecting millions of people world-wide with enormous direct and indirect healthcare costs (Katz, 2006). Long-term organ culture of human IVDs is essential for developing ex vivo models for study of IVD degeneration and repair. Using an ex vivo organ culture approach, the relationship between mechanobiology, disc matrix composition, metabolism and potential therapeutics can be better understood in the context of degenerative disease. We and others have demonstrated the benefits of using organ culture models coupled to bioreactors for studying IVD repair strategies (Gantenbein et al., 2015). Established bovine caudal disc bioreactor models are being used to gain mechanistic insights to disc degeneration as well as to determine feasibility of various disc repair strategies (Chan et al., 2013; Haglund et al., 2011; Illien-Junger et al., 2010; Jim et al., 2011; Pattappa et al., 2014; Paul et al., 2012; Walter et al., 2014). A recent study has shown the feasibility of long-term culture of intact human IVDs under cyclic loading (Walter et al., 2014). However, Walter et al. did not compare the effect of various magnitudes of 
cyclic loading on cell viability and extracellular matrix homeostasis. The present study will allow for simulation of physiological and super-physiological loading and culture conditions of the tissue to better address concerns for delivery of cell-based (Krock et al., 2015) or small molecular therapeutics (Mwale et al., 2014).

Minimally invasive experimental approaches to repair degenerate discs include cell-based therapies such as autologous NP cell or stem cell implantation (Illien-Junger et al., 2012; Kregar Velikonja et al., 2014; Leung et al., 2014). While obtaining autologous NP cells for therapeutic use remains a challenge, mesenchymal stems cells (MSCs) have gained much attention for IVD repair (Krock et al., 2015). Indeed, autologous and allogeneic bone marrowderived stem cells are currently being used in clinical trials and are showing promise for disc repair (Orozco et al., 2011; Yoshikawa et al., 2010). However, it remains to be determined as to whether stem cells differentiate into IVD cells to rebuild the tissue or if they release factors that both promote resident IVD cells to repair the tissue and block inflammatory cytokines present in the degenerate disc. Also, the effects of mechanical loading following stem cell implantation into discs needs to be determined.

We have previously established a whole-disc culture model system for healthy human IVDs, whereby vertebral bone is removed to expose the cartilage endplates allowing up to 4 months in culture (Gawri et al., 2011; Parolin et al., 2010). However, to establish this ex vivo organ culture model under simulated physiological conditions, a bioreactor was developed that facilitates culture of intact, healthy human IVDs in a controlled and dynamically loaded environment. The bioreactor is used in combination with our previously reported IVD harvesting method in which vertebral bone is removed to expose the cartilage endplates. Therefore, the goal of this study was to generate a physiological model for dynamic culture of intact human IVDs, where mechanisms of degeneration can be further elucidated and novel therapeutic strategies can be explored. We hypothesised that moderate dynamic loading schemes would most accurately present physiological loading conditions. Here, we determine IVD tissue integrity, cell viability and elastic mechanical properties under 3 different loading conditions. Furthermore, we show the suitability of this model towards cell supplementation for tissue repair under physiological conditions. Ultimately, we have introduced a novel pre-clinical platform to study mechanisms of IVD degeneration and repair using intact, viable human tissues thereby paving way for potential new therapies against painful disc degeneration.

\section{Materials and Methods}

\section{Tissue isolation}

Human IVDs were isolated as described from lumbar spine segments obtained with consent through the Transplant Quebec Organ Donation Program from individuals who had undergone sustained brain death (Gawri et al., 2011). Demographics are presented in Table 1. Briefly, the spines were radiographed and disc heights were calculated by 3 examiners using the Dabbs method (Dabbs et al., 1990). All spines were processed within $4 \mathrm{~h}$ post mortem, soft tissue

Table 1. Demographics for specimens used in study. Age of donors, cause of death, individual lumbar segments and IVDs used for each experiment. Disc heights were calculated from x-rays by three blinded evaluators using the Dabbs method. Degree of degeneration was evaluated post loading by combining a visual Thompson score with a measured sGAG content.

\begin{tabular}{|c|c|c|c|c|c|c|c|}
\hline Donor & Age & Gender & COD & Disc Levels & Grade & Ave. Height (cm) & Usage \\
\hline 1 & 33 & $\mathrm{M}$ & $\mathrm{ICH}$ & L2-3, L3-4, L4-5 & $3,3,3$ & $1.01,1.15,1.25$ & \multirow{8}{*}{ Loading } \\
\hline 2 & 53 & $\mathrm{M}$ & Thrombosis & L2-3, L3-4, L4-5 & $2,2,3$ & $1.09,1.08,1.21$ & \\
\hline 3 & 21 & $\mathrm{~F}$ & MVA & L2-3, L3-4, L4-5 & $2,1,3$ & $1.06,1.21,1.42$ & \\
\hline 4 & 44 & $\mathrm{~F}$ & CVA & L1-2, L2-3, L3-4 & $3,3,3$ & $1.07,1.09,1.33$ & \\
\hline 5 & 25 & $\mathrm{M}$ & MVA & L4-5 & 3 & $0.99,1.03$ & \\
\hline 6 & 10 & $\mathrm{~F}$ & Thrombosis & L2-3, L3-4, L4-5 & $3,2,2$ & $1.20,1.38,1.45$ & \\
\hline 7 & 21 & $\mathrm{M}$ & MVA & L2-3, L3-4, L4-5 & $3,2,2$ & $0.96,1.01,1.27$ & \\
\hline 8 & 58 & $\mathrm{M}$ & CVA & L2-3, L4-5 & 3,3 & $0.91,1.34$ & \\
\hline 9 & 26 & $\mathrm{M}$ & MVA & L1-2, L3-4 & 2,2 & $0.90,1.30$ & \multirow{3}{*}{$\begin{array}{c}\text { Stress } \\
\text { Profiling }\end{array}$} \\
\hline 10 & 49 & $\mathrm{~F}$ & MVA & L1-2, L2-3 & 3,3 & $0.93,0.95$ & \\
\hline 11 & 69 & $\mathrm{~F}$ & $\mathrm{ICH}$ & L2-3, L3-4 & 5,5 & $1.24,1.22$ & \\
\hline 12 & 55 & $\mathrm{M}$ & Cardiac Arrest & L2-3, L3-4, L4-5 & $3,3,3$ & $1.36,1.37,1.65$ & \multirow{4}{*}{$\begin{array}{c}\text { Cell } \\
\text { Implantation }\end{array}$} \\
\hline 13 & 67 & $\mathrm{M}$ & Cardiac Arrest & L3-4 & 3 & 1.19 & \\
\hline 14 & 29 & $\mathrm{M}$ & Cerebral Anoxia & L1-2, L2-3 & 3,3 & $1.08,1.18$ & \\
\hline 15 & 18 & $\mathrm{M}$ & Anaphylactic Shock & L3-4, L4-5 & 2,2 & $1.09,1.20$ & \\
\hline 16 & 50 & $\mathrm{~F}$ & Cerebral Haemorrhage & L1-2 & 3 & 0.80 & \multirow{2}{*}{$\begin{array}{l}\text { NP Cell } \\
\text { Isolation }\end{array}$} \\
\hline 17 & 27 & $\mathrm{M}$ & Cerebral Anoxia & L1-2 & 2 & 0.97 & \\
\hline
\end{tabular}

$\mathrm{ICH}=$ intracranial haemorrhage, $\mathrm{MVA}=$ motor vehicle accident, $\mathrm{CVA}=$ cardiovascular accident. 
and ligaments were removed, and the discs were isolated by parallel cuts close to the endplates leaving approximately $3 \mathrm{~mm}$ bone on each side of the discs. Discs were further processed using a high-speed drill (Foredom, Bethel, CT), fitted with a surgical fluted ball burr (Conmed Linvatec, Largo, FL) to remove bone and the adjacent calcified part of the cartilaginous endplate. They were processed until the cartilage endplates were fully exposed and the surface was soft and flexible without detectable calcified tissue. The discs were thoroughly rinsed in PBS containing $100 \mu \mathrm{g} /$ $\mathrm{mL}$ gentamycin and $2 \times$ Fungizone (both from Invitrogen, Burlington ON), followed by 2 washes in Hanks' balanced salt solution (HBSS, Sigma) also containing $100 \mu \mathrm{g} /$ $\mathrm{mL}$ gentamycin (Invitrogen) and $2 \times$ Fungizone. Washed discs were then placed in sterile polypropylene specimen containers $(80 \mathrm{~mL}$ volume, STARPLEX Scientific, Etobicoke, ON) containing culture media (Dulbecco's Modified Eagle's Medium with L-glutamine and $15 \mathrm{mM}$ HEPES, supplemented with $5 \%$ foetal bovine serum, $50 \mu \mathrm{g} / \mathrm{mL}$ gentamycin $50 \mu \mathrm{g} / \mathrm{mL}$ L-ascorbate) at a ratio of $3.5 \mathrm{~mL}$ of media per gram of tissue weight (Gawri et al., 2011).

\section{Stress profilometry}

We have previously designed a bioreactor for loading and culture of bovine discs. That system utilises loading platens covering $60 \%$ of the disc area. This design was established to give optimal load-transfer to bovine discs, which in contrast to the flat human discs, have a concave shape when prepared with cartilaginous endplates intact (Haglund et al., 2011). To establish optimal load-platens for human discs with varying degree of degeneration, stress-profilometry was performed on, two healthy, two mildly degenerate and two severely degenerate discs (L2-L3, L3-L4, L1-L2 from each of three donors) (Fig. 7). The spinal segments were radiographed to assess the grade of degeneration. Stress profilometry was performed as previously described (Gawri et al., 2014a; Haglund et al., 2011). This was used to quantify the axial stress across a disc diameter and to identify and optimise platens for axial load-transfer across the NP and AF of the discs. Six discs were used for analysis: 2 non-degenerated, 2 moderately degenerate and 2 severely degenerated (Table I). The surface areas of the discs were calculated using Image $\mathrm{J}$ software (National Institutes of Health, Bethesda, Maryland, USA). Flat surface, porous interface platens were used to sandwich the isolated discs. A healthy disc was first tested with the bony endplate intact serving as the native control with the platen covering the entire flat cut bone surface. In the cartilage endplate group, two different porous platen designs were used. For the "partial coverage" (part), platens were selected from an array of $1 \mathrm{~mm}$ increment platens, to match a $50 \%$ normalised disc cross-sectional area. "Full coverage" platens $(f u l l)$, similar to the bony endplate group, covered with overlap the disc's entire endplate.

Controlled axial disc loading was carried out using a Mini Bionix 858 mechanical testing system (MTS, Eden Prairie, MN). All discs were preconditioned for $5 \mathrm{~min}$ at $0.1 \mathrm{MPa}$ load, and then stress profilometry was performed at 0.6 MPa. As described (Haglund et al., 2011; McNally et al., 1992), a needle with a pressure sensor mounted close to the tip was inserted laterally through the annulus, in the mid plane of the disc, until the sensor was visibly perforating the opposite lateral annular region. The needle was coupled to a resistor-based linear position sensor. The needle was steadily and slowly drawn backwards across the entire disc with the sensor facing upwards ("vertical") or sideways ("horizontal"). Horizontal and vertical stress profiles were recorded for each disc first with the full coverage platen followed by recordings with the partially covering platens. Positional horizontal and vertical stress profiles were recorded with both partial and full coverage platens. Positional data and pressure data was plotted to generate the stress profiles.

\section{Bioreactor design, culture chamber and loading frame}

The bioreactor system was a modified version of the one previously described for bovine disc culture (Haglund et al., 2011). It consists of two sub-systems: a culture chamber used for culturing, and a loading frame allowing for application of controlled axial loading while measuring tissue height displacement. The system was designed as triple units, with each bioreactor controlled independently.

The components of the culture chambers were basically as described earlier (Haglund et al., 2011) (Fig. 1A). The disc was sandwiched between a top and bottom porous platen, which in this design was modified to have a fixed diameter of $58 \mathrm{~mm}$ covering the entire disc surface area. The platens were fitted in holders. The top holder extended to a vertical plunger, with a central media inlet through the top porous platen, allowing for media to be circulated from the top down. The bottom holder was attached to the base plate with another central media inlet, allowing the media to be pumped into the bottom entry port as well as the top. A slightly elevated fluid outlet was located at the bottom of the culture chamber.

The loading frame was modified as follows, and the main components are displayed in Fig. 1A. The load cell was changed to a compact through-hole type (Model LC8200; Omega, Stamford, CT) that was placed at the bottom of the frame instead of at the top. The pneumatic rolling diaphragm linear actuator and the external linear variable differential transformer were replaced by a low friction position feedback air cylinder, with a built-in linear resistive transducer (Model PFC-316-B; Bimba Manufacturing, University Park, IL). The proportional pressure control valve was changed to a Sentronic D directoperated 3-way proportional valve (Model 6086C0111; Numatics, Novi, MI).

\section{Disc culture}

The isolated discs were cultured without external load for 2-7 d to avoid potential contamination to the bioreactors. They were then transferred to the bioreactors and were loaded statically for $48 \mathrm{~h}$ at $0.1 \mathrm{MPa}$ allowing the discs to creep, thereby equilibrating its water content to the external load and intrinsic swelling properties. Twentyone healthy human discs were divided into three groups: low (LD), medium (MD), and high (HD). Discs used in the study were radiographed. Only discs with maintained disc height and no signs of degeneration or osteophytes 


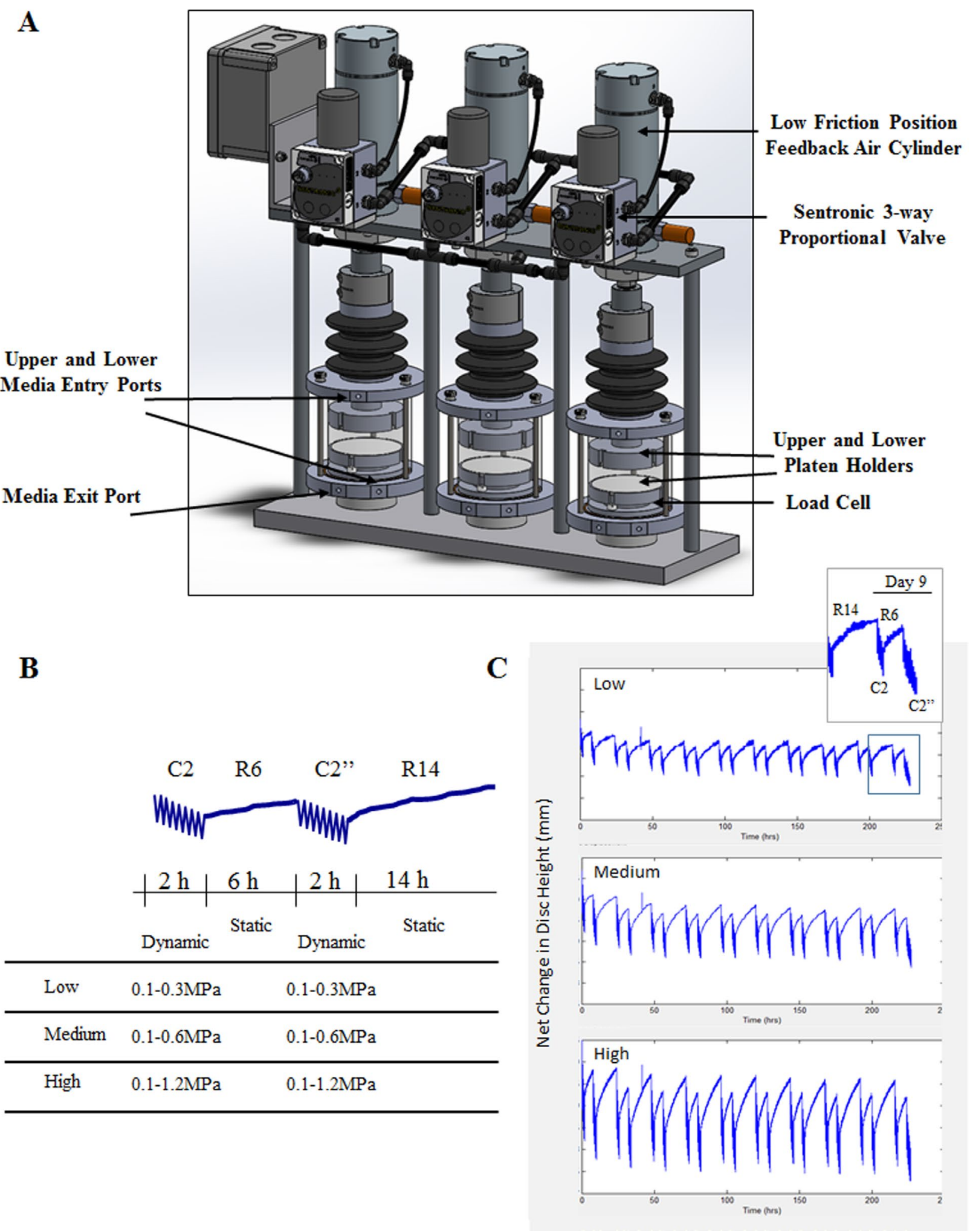

Fig. 1. Bioreactors for dynamic culture of human lumbar IVDs. (A) CAD designed schematic of bioreactor set up, modified from (Haglund et al., 2011) to accommodate human lumbar IVDs. Culture chamber, frame, cover plates, platens and holders, actuators and load cells are shown. (B) Schematic representation of the three loading schemes used. Within a $24 \mathrm{~h}$ period there are 4 cycle segments: C2 represents the initial $2 \mathrm{~h}$ of dynamic cyclic loading; R6 represents $6 \mathrm{~h}$ of resting static load; C2" represents the second $2 \mathrm{~h}$ of dynamic cyclic loading; R14 represents $14 \mathrm{~h}$ of resting static load. LD indicates low dynamic loading; MD indicates medium dynamic loading; HD indicates high dynamic loading. The different load magnitudes are indicated and all applied at a frequency of $0.1 \mathrm{~Hz}$. Resting periods for static load are held constant at $0.1 \mathrm{MPa}$. (C) Representative curves for height-loss and recovery during respective dynamic and static loading over $10 \mathrm{~d}$ of culture. Each tick mark on the y-axis represents $1 \mathrm{~mm}$. Inset enlarged image indicates the 4 cycles of the load segments at day 9. 
were selected for this part. The discs were then inspected visually at the termination of the experiment to determine Thompson grade, and the sGAG content was correlated with Pfirrman grade according to our previous report (Mulligan et al., 2015). We could confirm that the discs at termination were of Thompson grade 2-3 with a sGAG content comparable to a Pfirrman grade 2-3 (listed in Table 1). Dynamic, compressive loads were applied to the groups cycling in a sinusoidal pattern between $0.1 \mathrm{MPa}$ and 0.3 , 0.6 or $1.2 \mathrm{MPa}$, respectively, for two periods of $2 \mathrm{~h}$ each. The dynamic compressive load periods were interrupted by recovery periods of $6 \mathrm{~h}$ and $14 \mathrm{~h}$ respectively, maintaining a low-static 0.1 MPa load (Fig. 1B). The loading scheme was repeated for 10 consecutive days (representative curves, Fig. 1C). Disc weight was recorded at harvest, after the preconditioning period and at termination. Changes in disc height and axial load data were sampled continuously at $0.2 \mathrm{~Hz}$.

\section{Cell viability}

After the $10 \mathrm{~d}$ of dynamic culture, $6 \mathrm{~mm}$ cores were taken from the NP and inner AF (iAF) regions, using a biopsy punch (Acuderm Inc., Ft. Lauderdale, FL). Half of the tissue core was incubated in serum-free medium containing calcein AM and ethidium homodimer fluorescent dyes (Live/Dead ${ }^{\circledR}$, Invitrogen, Burlington, ON), according to the manufacturer's instructions. A $0.75 \mathrm{~mm}$ slice was taken through the centre of the core, and cell viability was evaluated using an inverted confocal laser scanning microscope (CLSM) (Zeiss LSM 510). 20 consecutive $6 \mu \mathrm{m}$ sections were imaged. The CLSM stacks were split into single images and 5 images were selected, merged and saved as single colour JPEG file (red and green separate) and the labelled cells were quantified separately using the CellC software (Matlab source-code, Tampere University of Technology, https://sites.google.com/site/cellcsoftware/) (Selinummi et al., 2005). The ratio of live to dead cell was calculated from the proportion of green and red cells.

\section{sGAG and protein extraction and analysis}

The remaining half of the $6 \mathrm{~mm}$ tissue cores of NP and inner AF tissue were thinly sliced with a scalpel blade and extracted on a wet-weight per volume basis using 15 volumes extraction buffer (4 M guanidinium chloride, $50 \mathrm{mM}$ sodium acetate, $\mathrm{pH} 5.8,10 \mathrm{mM}$ EDTA, and COMPLETE $^{\circledR}$ protease inhibitors [Roche, Laval, QC]). Tissue samples were incubated for $48 \mathrm{~h}$ at $4{ }^{\circ} \mathrm{C}$ under continuous agitation. The extracts were then cleared by centrifugation at $16,000 \times g$ for $30 \mathrm{~min}$.

\section{DMMB assay}

Sulphated glycosaminoglycans (GAGs) were quantified from tissue extracts by a modified dimethyl methylene blue (DMMB) assay (Mort and Roughley, 2007). Samples were diluted to fall in the middle of the linear range of the standard curve and results expressed per mg of tissue weight. In order to adjust for any interference by $\mathrm{GuHCl}$, an equivalent amount of $4 \mathrm{M} \mathrm{GuHCl}$ was added to the standards. All results were normalised to tissue wet weight.

\section{Western blot}

Aliquots of $5 \mu \mathrm{L}$ of NP and AF tissue extracts (described above) were prepared for SDS-PAGE by precipitation using 9 volumes of $100 \%$ ethanol. Precipitates were recovered by centrifugation $\left(30 \mathrm{~min}\right.$ at $\left.4{ }^{\circ} \mathrm{C}\right)$. Pellets were washed once each with $75 \%$ ethanol and $95 \%$ ethanol before being lyophilised and re-dissolved in $25 \mu \mathrm{L}$ of $50 \mathrm{mM}$ sodium acetate, $\mathrm{pH}$ 6.0. Sample buffer was added directly after digestions, and the proteins were fractionated on 4-12\% SDS-PAGE gradient gels (NuPage Tris-Glycine, Invitrogen). Proteins were transferred to nitrocellulose membranes and blocked with $3 \%(\mathrm{w} / \mathrm{v})$ skim milk powder in TBST $(0.01 \mathrm{M}$ Tris- $\mathrm{HCl}, 0.15 \mathrm{M}$ $\mathrm{NaCl}, 0.1 \%$ Tween 20, pH 7.6). Antisera were diluted $1: 1000$ in the same buffer containing $3 \%$ bovine serum albumin (BSA). Immunoblotting was performed using specific polyclonal antibodies against chondroadherin as previously described (Akhatib et al., 2013) (anti-CHAD, a gift from Dick Heinegard) and rabbit polyclonal antibodies against collagen type II (1:500, Abcam, Cambridge, MA, USA). HRP-conjugated Rabbit IgG was used as the secondary antibody (1:5000, Cell Signaling Technology, Danvers, MA, USA). Bound antibodies were detected by chemiluminescence using the ECL system (Western Lightning Plus, Perkin Elmer, Woodbridge, ON, Canada), using a LAS4000 image analyser (GE Healthcare, Baie d'Urfe, QC, Canada). ImageQuant TL software was used for pixel quantification. Total protein was determined in tissue extracts by the Bradford protein assay according to the manufacturer's instructions (Thermo Scientific).

\section{Injection of hydrogel and NP cell-suspension}

Six human lumbar discs in total (age range 29-67) were used to test the feasibility of cell-injection therapy studies using the bioreactor system. NP cells were isolated as described (Gawri et al., 2014b) from dissected NP tissue from 2 individual donors (ages 27 and 50). Cells were maintained in culture and cells used in passage 4 and 5 from each donor, respectively. Prior to injection into isolated lumbar IVDs, cells were labelled with a fluorescent membrane dye (Vybrant DiI, Life Technologies, Burlington, ON) according to manufacturer's instructions. One million labelled cells were suspended in a thermoreversible poly( $N$-isopropylacrylamide) derivative of hyaluronic acid hydrogel (HA-pNIPAM) as described (D'Este et al., 2012; Peroglio et al., 2013; Peroglio et al., 2012), and approximately $300-400 \mu \mathrm{L}$ of the suspension $(\sim 300,000$ cells) were injected laterally into the discs using a $26 \mathrm{~g}$ needle. Injected discs were placed under static load (0.1 MPa) for $48 \mathrm{~h}$ and then dynamically loaded using the MD protocol described above for 3, 7 and $14 \mathrm{~d}$. After loading was completed, $1.5 \mathrm{~mm}$ sagittal sections were taken from the centre portion of the discs, and tissue was assessed by laser scanning microscopy for localisation of injected, labelled NP cells.

\section{Statistical analysis}

All statistical analysis was performed using Prism 6.0 software (GraphPad Software, Inc., La Jolla, CA). For 
all comparisons of effects of LD, MD and HD loading, NP were assessed separately from AF samples. One-way ANOVA followed by multiple comparisons post-hoc tests were performed. All $p$ values less than 0.05 were considered statistically significant.

\section{Results}

\section{Optimisation of loading platens for the human IVD bioreactor system}

Healthy human lumbar discs were isolated from consented organ donors as described (Gawri et al., 2011), and were distributed for experimentation as indicated (Table 1). The discs were loaded at $0.6 \mathrm{MPa}$, with either full-coverage platens or with platens covering $60 \%$ of the area. Partialcover platens showed stable, uniform pressure across the disc diameter only for healthy discs and were non-uniform and inconsistent for mildly and severely degenerate discs. Full coverage platens showed uniform and consistent pressure across the disc diameter, with severely degenerate discs showing slightly less total disc pressure than healthy and mildly degenerate discs (Fig. 7).

\section{Dynamic loading of human IVDs in the bioreactor system}

Isolated discs were cultured without loading for 2-7 days prior to loading in the bioreactors. They were then subjected to $48 \mathrm{~h}$ of static loading at $0.1 \mathrm{MPa}$ to equilibrate the tissue to a resting height. Three different loading regimes were applied (LD: 0.1-0.3 MPa; MD: 0.1-0.6 MPa and HD: 0.1-1.2 MPa; Fig. 1B) consisting of $2 \mathrm{~h}$ dynamic loading, $6 \mathrm{~h}$ static rest, $2 \mathrm{~h}$ dynamic loading, and $14 \mathrm{~h}$ of static rest for $10 \mathrm{~d}$. Fig. 1C shows representative curves measuring loss- and gain-of disc height during the loading schemes over time. After $10 \mathrm{~d}$ of LD, MD and HD loading, height changes during dynamic loading and static recovery periods were assessed. Increased disc compression and subsequent re-swelling was observed at higher dynamic loads (1.2 MPa >0.6 MPa >0.3 MPa) (Fig. 2A). A uniform disc-height-recovery of about $63 \%$, regardless of the loading amplitude, was recorded during the $6 \mathrm{~h}$ recovery period compared those recorded after the $14 \mathrm{~h}$ recovery period (Fig. 2B). Overall there was a trend $(p=0.08)$ for a higher relative height recovery at higher measured NP GAG concentrations (not shown), although the linear correlation was quite weak $\left(r^{2}=0.17\right)$. Interestingly, the total disc height loss over the culture period was not significantly different between the groups (Fig. 2C).

Overall, and similarly to relative height recovery shown above, there was again a trend for $(p=0.07)$ dependency for less absolute disc height loss at higher measured GAG concentrations (not shown). However, the linear correlation was again quite weak $\left(r^{2}=0.18\right)$.

Tissue weight was recorded immediately after isolation, then again after non-loaded pre-culture and finally at the end of the last load cycle, before allowing the discs to recover. The $\mathrm{LD}, \mathrm{MD}$ and $\mathrm{HD}$ groups weight values increased by $+26.69 \%$, $+27.28 \%$ and $+28.86 \%$, respectively, from isolation to the end of pre-culture. At the end of the final load cycle, they had lost the weight they

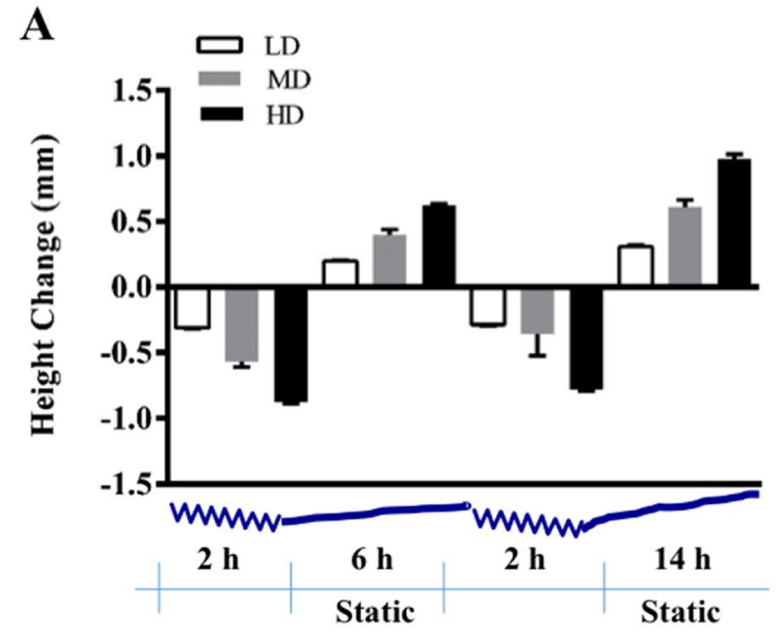

B

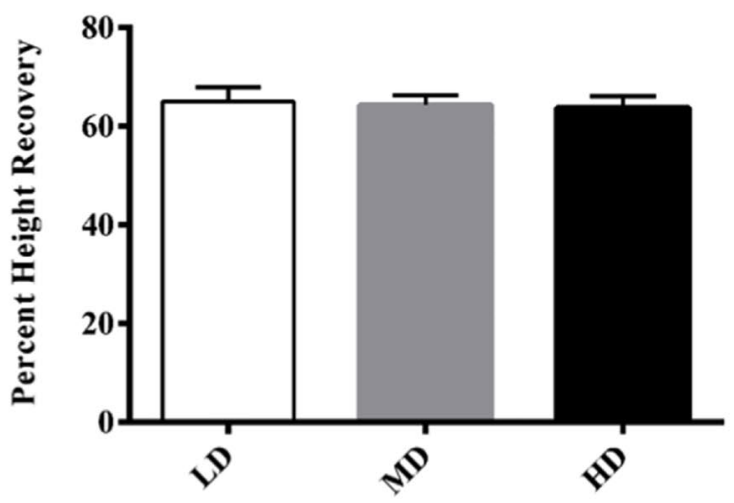

C

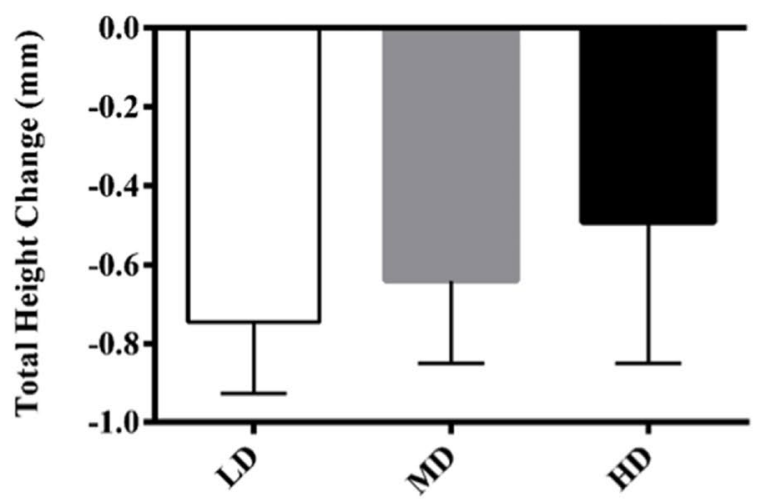

Fig. 2. Biomechanical properties of dynamically cultured human IVDs. (A) Average total height-loss and recovery for each loading group, per cycle segment within the $24 \mathrm{~h}$ scheme with schematic representation of load protocol below. After dynamic segments, discs lose weight and height, while they gain weight and height during resting segments. (B) Average percent height recovery comparing R6 to R14 cycle segments over $10 \mathrm{~d}$. (C) Average cumulative height change between that measured at R14 of day 9 (there is no R14 for day 10) and R14 after day 1 of loading. Error bars represent \pm SD. Experimental $n=7$ for each loading group (LD, MD and HD). One-way ANOVA and post-hoc tests. 
Fig. 3. IVD cell viability following 10 days of dynamic culture. (A) Representative laser scanning confocal images of NP and inner AF (iAF) samples subjected to Live/Dead assay. Green labelled cells (calcein AM) indicate live cells, while red labelled (ethidium homodimer) indicate dead cells. Scale bar $=200 \mu \mathrm{m}$. (B) Quantification of cell viability in the NP and iAF for all IVDs following the $10 \mathrm{~d}$ of dynamic LD, MD and HD loading ( $n=7$ for each group). Error bars represent \pm SD. ${ }^{b}$ indicates $p<0.05$, one-way ANOVA and posthoc tests.
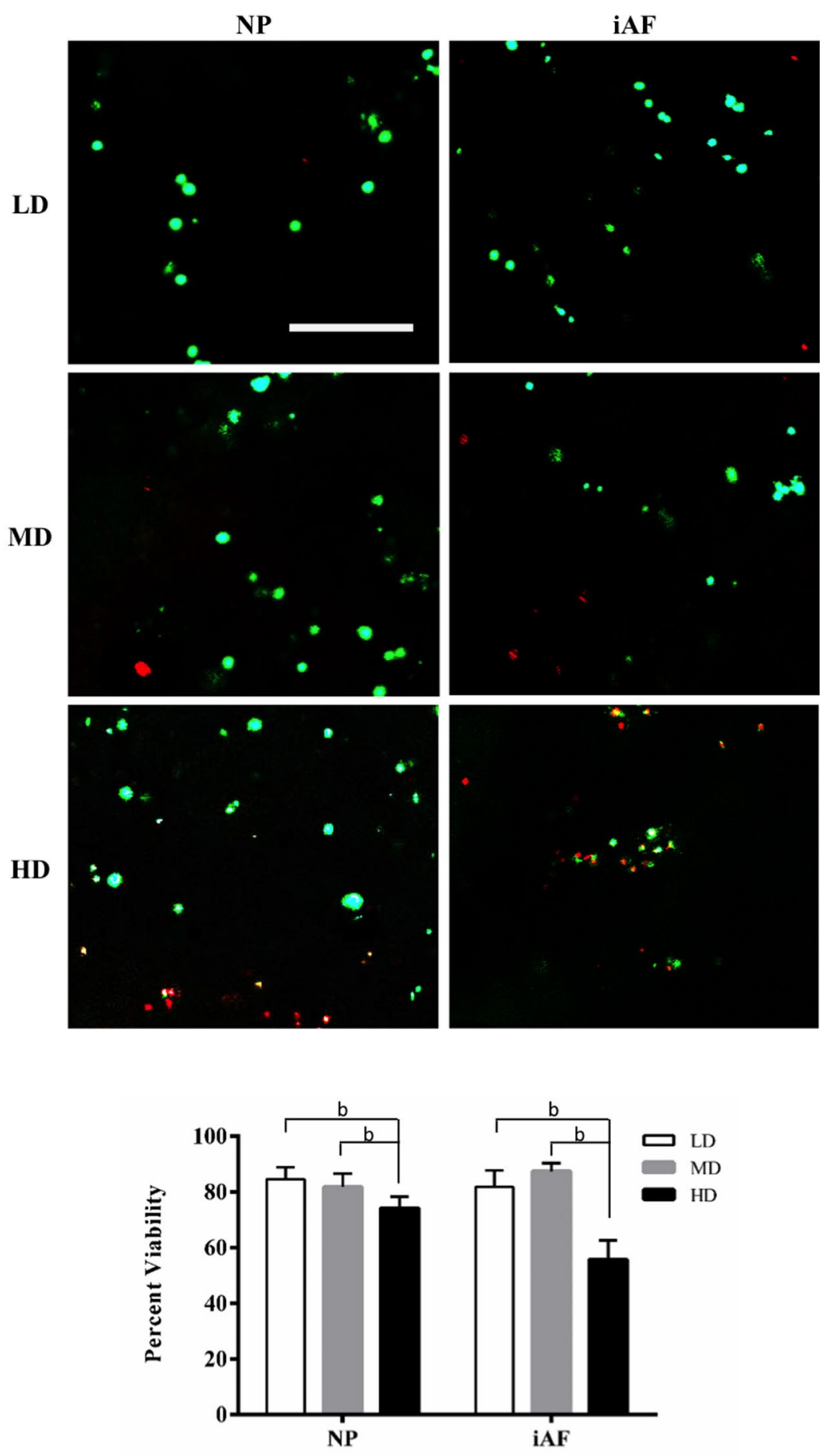

Table 2. Disc weight recordings from time of disc harvesting, unloaded culture period and the end of bioreactor loading cycles at $\mathrm{C} 2$, day 9 .

\begin{tabular}{|l|c|c|c|c|c|c|}
\hline & $\begin{array}{c}\text { \% difference in weight } \\
\text { between unloaded } \\
\text { culture and isolation }\end{array}$ & \pm & $\begin{array}{c}\text { \% difference in weight } \\
\text { between C2, day 9 } \\
\text { from unloaded culture }\end{array}$ & \pm & $\begin{array}{c}\text { \% difference in } \\
\text { weight between C2 } \\
\text { day 9 and isolation }\end{array}$ & \pm \\
\hline LD & +26.69 & 16.41 & -19.82 & 6.05 & +0.14 & 7.72 \\
\hline MD & +27.28 & 3.91 & -26.79 & 10.19 & -5.79 & 7.02 \\
\hline HD & +28.86 & 12.56 & -29.92 & 3.26 & -8.09 & 8.00 \\
\hline
\end{tabular}

gained during pre-culture. The discs displayed a $-19.82 \%$, $-26.79 \%$ and $-29.92 \%$ lower weight than when loading started. The weight change at the end of the final load cycle was $+0.14 \%,-5.79 \%$ and $-8.09 \%$ compared to weight at isolation (Table 2). Since discs were harvested at the end of the second load cycle, a net weight loss was expected. This was the case for MD and HD loaded discs while LD loaded disc retained a slightly higher weight than at isolation. 
Biological responses in loaded human IVDs

To determine the effects of the bioreactor LD, MD and HD loading regimes on cell viability, the fluorescent Live/Dead assay was performed. After $10 \mathrm{~d}$ of dynamic loading, LD and MD showed similar viability in NP (approximately $85 \%$ and $84 \%$, respectively); however, HD loading caused a significant drop in viability (approximately $73 \%$ ). LD and MD loading showed similar viability in the iAF (approximately $75 \%$ and $81 \%$, respectively), which was significantly reduced under HD loading conditions to approximately $61 \%$ (Fig. 3 ).

To assess the effects the loading regimes have on matrix homeostasis, sGAG content within the NP and iAF was investigated. Sulphated GAG content measured in the NP and iAF (Fig. 4) was not statistically different between the loading groups. To assess the effects of the loading regimes on IVD matrix homeostasis, chondroadherin (CHAD) and newly synthesised collagen type II protein levels were evaluated within the NP and iAF tissues (Fig. 5). CHAD has been shown to be a marker for matrix degradation in degenerative disc disease (Akhatib et al., 2013), where a specific C-terminal antibody can detect the full-length

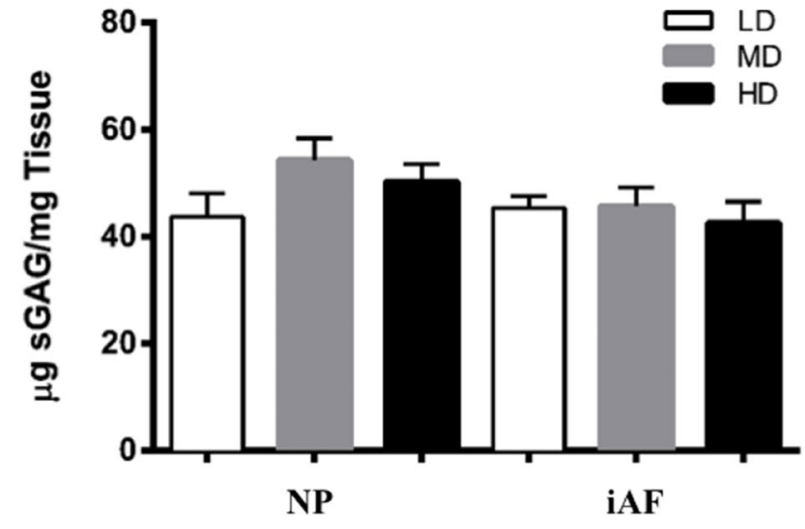

Fig. 4. Glycosaminoglycan content of IVDs following $10 \mathrm{~d}$ of dynamic culture. NP and iAF samples were extracted on weight per volume basis in $\mathrm{GuHCl}$ and subjected to quantitative DMMB assay. Average sulphated glycosaminoglycan (sGAG) per tissue weight is plotted for LD, MD and HD cultured discs $(n=7$ for each group). Error bars represent $\pm \mathrm{SD}$. No significant differences were observed, ANOVA and post-hoc analysis.

A
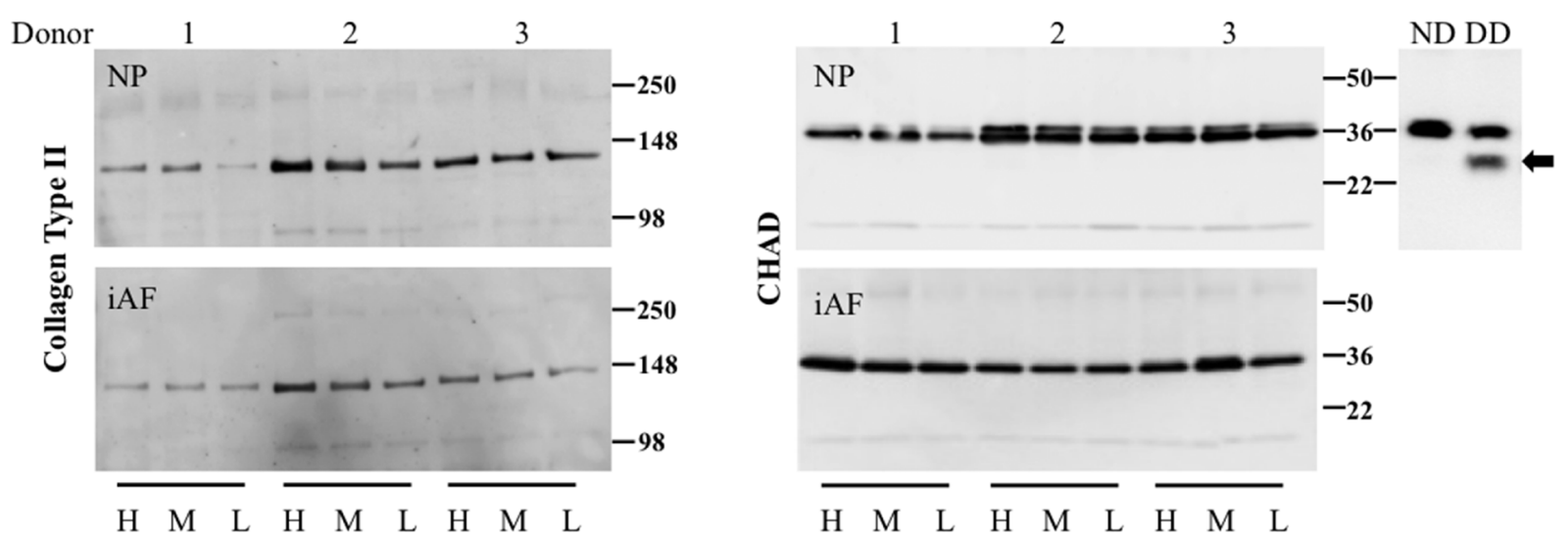

B
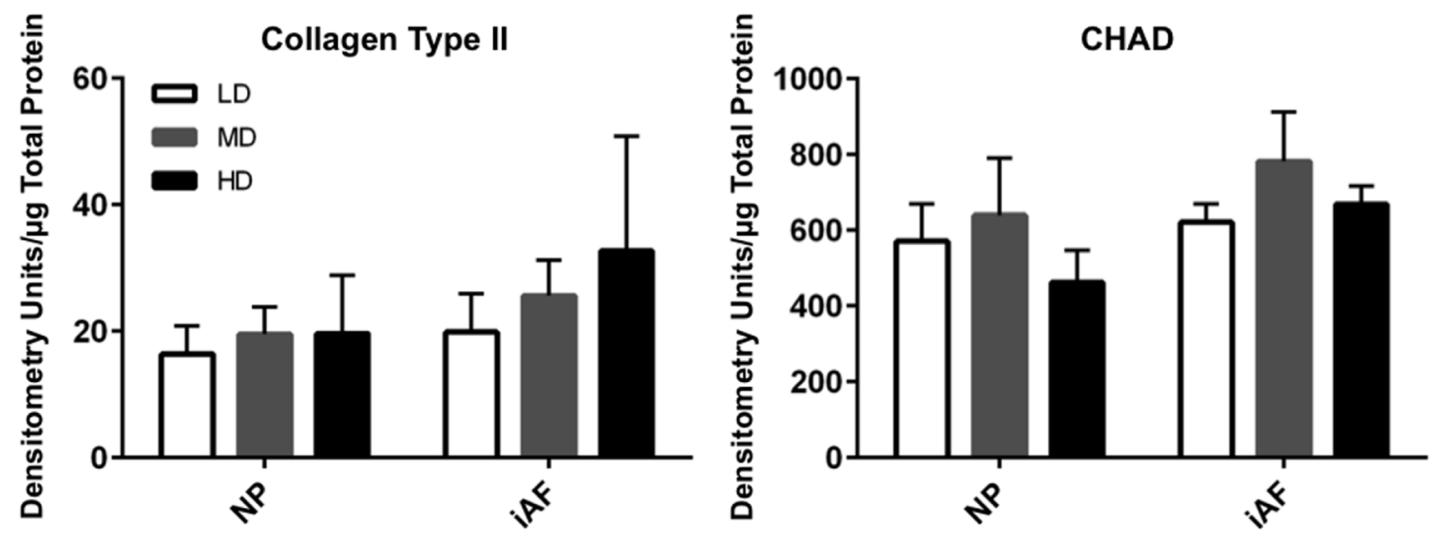

Fig. 5. Assessment of collagen type II synthesis and chondroadherin expression and stability in IVDs following dynamic culture. (A) Representative western blots probing for collagen type II and CHAD in NP and iAF samples from $\mathrm{LD}, \mathrm{MD}$ and HD loading. The inserted blot is showing intact (36 KDa) and fragmented (28 KDa, arrow) CHAD in non-degenerate (ND) and degenerate (DD) tissue. (B) Densitometry analysis of collagen type II synthesis and $\mathrm{CHAD}$ normalised to total protein ( $n=6$ for each group). Error bars represent $\pm \mathrm{SD}$. No significant differences were observed; one-way ANOVA with post-hoc test. 
A

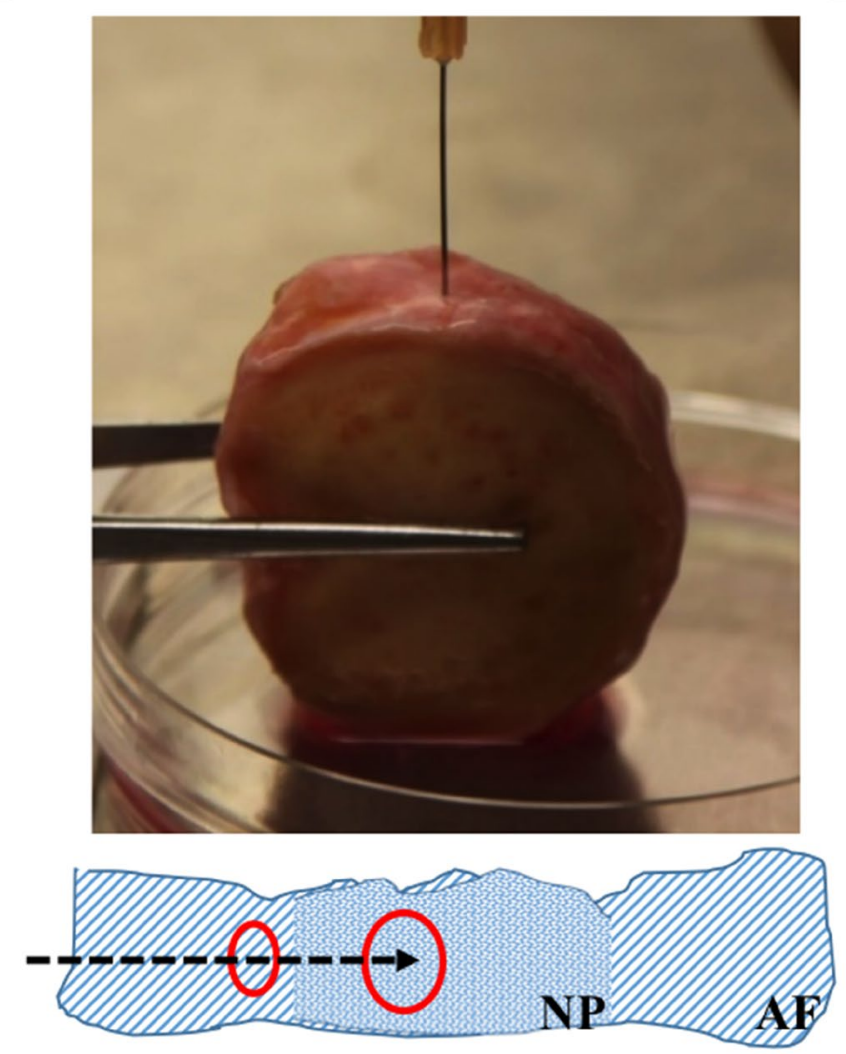

B
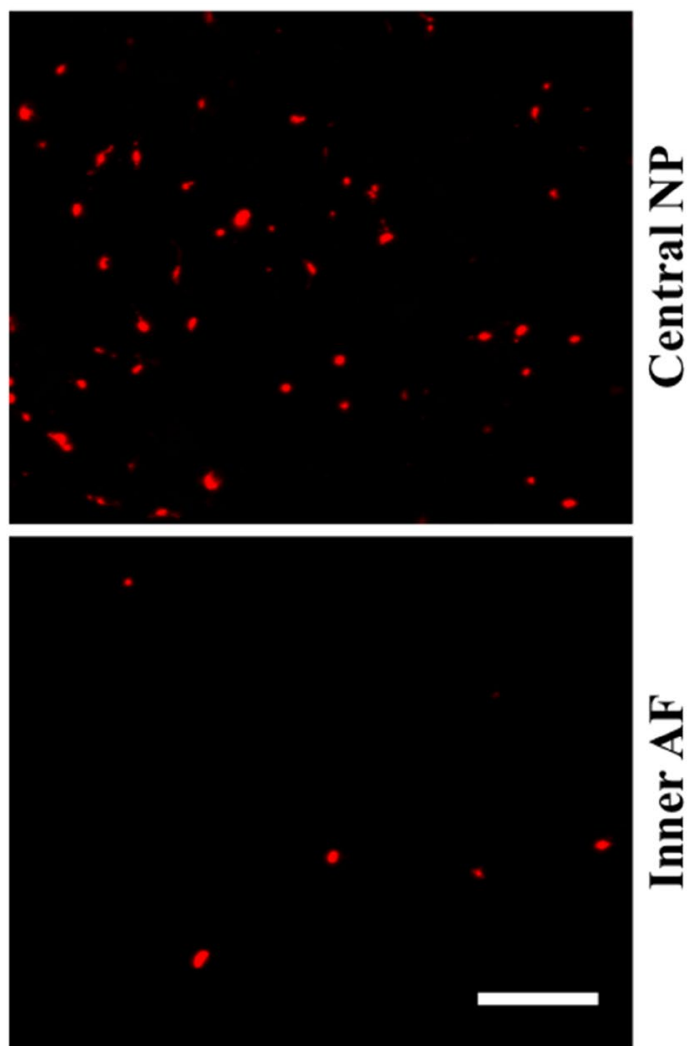

Fig. 6. Cell implantation and localisation following $14 \mathrm{~d}$ of MD culture. Human NP cells were isolated from lumbar IVDs, labelled with a fluorescent membrane dye and suspended in HA-pNIPAM thermoresponsive hydrogel for implantation into isolated IVDs. (A) Representative image of a NP cell/hydrogel suspension being injected into an isolated human lumbar IVD. Schematic indicates the general needle track direction as well as regions (smaller red circle for iAF and larger red circle for NP) where confocal images are acquired for the representative images in panel B. (B) Representative confocal images showing localisation of fluorescently labelled (red), implanted NP cells in human lumbar IVDs after $14 \mathrm{~d}$ in MD culture. Cells remain mainly localised to delivery site within the NP, with few cells found along needle tracks.

protein and a smaller fragment in degenerate samples. That study went on to show that in degenerate discs, CHAD becomes cleaved by HTRA1 enzyme activity to yield a smaller $28 \mathrm{kD}$ fragment. MD and HD loading slightly, but insignificantly increased newly synthesised collagen type II compared to LD loading. MD loading slightly, but insignificantly, elevated full-length CHAD levels in both the NP and $\mathrm{iAF}$, as compared to LD and HD samples. No CHAD fragmentation was observed under any of the loading conditions. Taken all together, the LD and MD loading regimes on IVDs cultured over $10 \mathrm{~d}$ within the bioreactor show the feasibility of long-term whole-disc organ culture under physiological loading conditions while maintaining viability and matrix stability.

\section{NP cell-seeded hydrogel implantation to human IVDs under physiological loading}

We next determined the suitability of this ex vivo model of physiological disc organ culture as a platform to test tissue repair strategies for IVD degeneration. The MD loading regime was selected as it provided the greatest retention of biological and mechanical properties. Labelled, isolated primary human NP cells were suspended in HA-pNIPAM hydrogel. The cell/hydrogel suspensions (up to $400 \mu \mathrm{L}$ ) were readily injected laterally through the AF into the nucleus of the isolated discs, without any noticeable "backpressure". The cell/gel suspension thermo-solidified rapidly upon delivery into the discs cultured at $37^{\circ} \mathrm{C}$, as leakage was neither observed from the delivery site, nor within the surrounding culture media. To determine whether cell/ gel injections would remain localised after physiological loading, injected discs were cultured for 3, 7 and $14 \mathrm{~d}$ under MD loading conditions. 1 disc was cultured for $3 \mathrm{~d}, 3$ discs for $7 \mathrm{~d}$ and 4 discs for $14 \mathrm{~d}$. Upon dissection, HA-pNIPAM was macroscopically identified due to different coloration compared to AF/NP tissue. Microscopic analysis revealed a majority of cells were found in the centre of the disc within or immediately surrounding the hydrogel area at all time points (Fig. 6, $14 \mathrm{~d}$ time point shown). Very few cells were also identified in the iAF or the periphery. Several samples were co-stained with Live Dead assay, and there was no sign of dead labelled cells that were injected into the discs at any time point (data not shown). 
$\mathbf{A}$
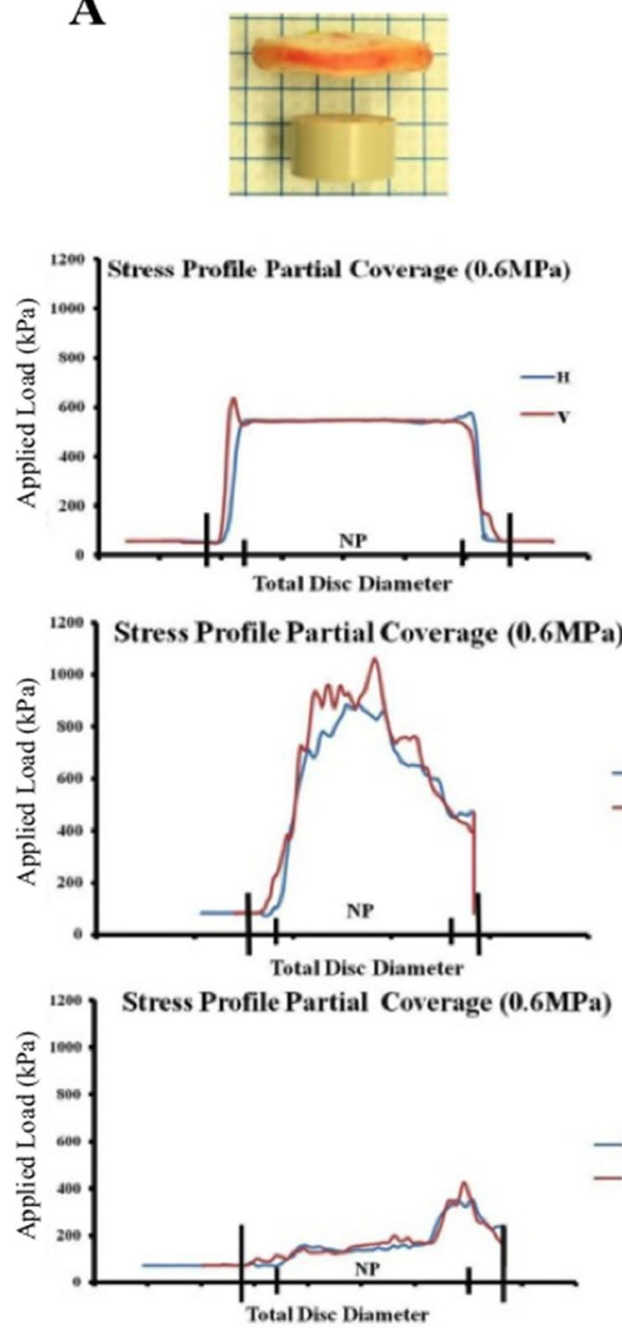

B
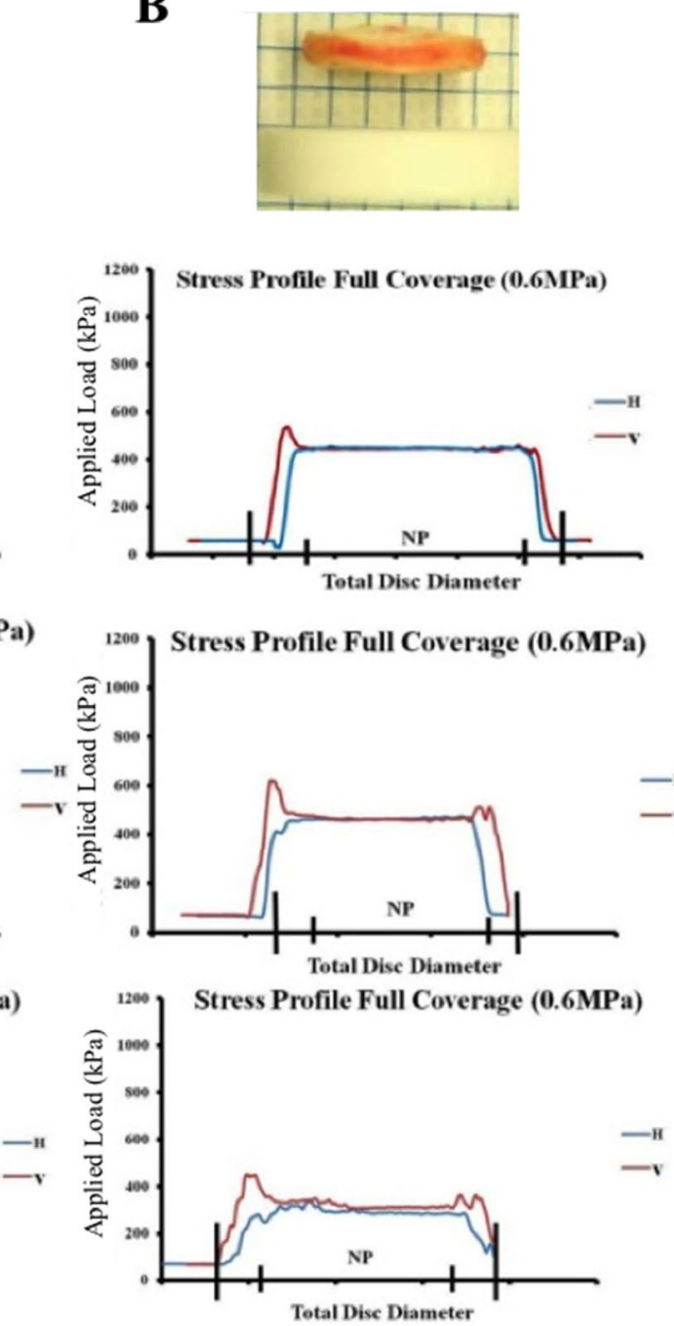

No Degeneration

Mild Degeneration

Severe Degeneration

Fig. 7. Stress profilometry of human lumbar IVDs on varying coverage platens. Discs without signs of degeneration $(n=2)$, mild degeneration $(n=2)$ or severe degeneration $(n=2)$ were subjected to $0.6 \mathrm{MPa}$ of load on $(\mathbf{A})$ partial coverage or (B) full coverage platens. Stress profilometry was measured as previously reported (Haglund et al., 2011). Based on profiles presented, full coverage platens were chosen to use in bioreactor cultures for human IVDs.

\section{Discussion}

Generation of an ex vivo, human whole-organ culture model replicating physiological conditions of the IVD is a necessary platform on which to rapidly assess feasibility and validity of numerous novel treatment options for degenerative disc disease. Such a model system is also essential to better identify mechanisms of human disc degeneration. In the present study, we have developed a bioreactor culture system, which subjects intact human IVDs to physiological loading conditions. The ex vivo organ culture model maintains physiological disc biomechanics, cell viability, and extracellular matrix integrity. Additionally, this culture system allows for cell implantation strategies for disc repair to be evaluated - studies previously performed in animal models or extremely costly clinical trials.

The axial load magnitudes applied in the present study were normalised to the varying disc cross-sectional surface areas, and were chosen to fall within in a range of $0.3 \mathrm{MPa}$ to 1.2 MPa peak load. This corresponds to load magnitudes observed in daily activities comparable to a sedentary life style for the lower end, and to strenuous physical activity for the higher end (Wilke et al., 2003). From our initial studies, using bovine caudal discs (Gawri et al., 2014a; Haglund et al., 2011), as well as from previous data on cell viability after long-term culture of human IVDs, with and without bony endplates (Gawri et al., 2011), we were initially concerned that discs retaining vertebral bony endplates would not be able maintain cell viability under our physiological axial loads over extended periods of time. We therefore removed vertebral bone, exposing the cartilage endplates of the discs to ensure long-term viability in our model. In this way, we are able to capitalise on our ability to obtain very healthy, intact human lumbar discs.

Using this unique human organ culture system, two distinct models can then be generated: 1) induced degeneration to identify mechanisms of degenerative disc disease, reduced cellularity and generation of inflammatory and pain mediators; 2) induced degeneration followed by disc repair strategies to identify novel repair options and therapeutics. In both cases, control, healthy discs 
with optimal cell viability are obtained from the same donor, which can greatly reduce experimental variability. It is also important to note that discs of varying degree of degeneration are often obtained within an individual donor (Adams et al., 2015). In these cases, a third model may be introduced, where induction of degeneration is not required and cell therapies can be tested directly on these degenerate discs. Furthermore, non-degenerate discs from the same donor can still be used as the optimal control as a standard for disc repair.

In addition to the cartilage endplate model used in the present study, disc organ-culture models with vertebral bony endplates intact have been described. Using healthy discs in an ovine model for physiological organ culture of IVDs, vertebral bone is kept intact to avoid swelling of discs and help maintain constant disc heights during experimentation (Junger et al., 2009). Yet, in a similar study with caprine lumbar discs with some vertebral bone intact, viability can be severely reduced under various loading conditions (Paul et al., 2013). It has been recently reported that retention of about $73 \%$ cell viability is possible in human discs cultured under physiological loading conditions with minimal bony endplates intact, for up to three weeks (Walter et al., 2014). Nonetheless, our results similarly demonstrate that under LD and MD loading conditions more than $80 \%$ cell viability can be maintained throughout the disc. Only at the higher loads of 1.2 MPa did viability drop, more so in the AF compared to the NP. This result suggests that our HD loading scheme may be above a physiological level, even though the peak load is not excessive. The results of the present study are consistent with other reports where loss of cell viability was found with increased load magnitude or frequency (Alkhatib et al., 2014; Dudli et al., 2014; Dudli et al., 2012; Paul et al., 2013; Walter et al., 2011).

Maintenance of long-term disc height does not seem be compromised during our culture experiments. Discs subjected to higher loads, up to $1.2 \mathrm{MPa}$, seem to recover better from load-induced non-elastic height loss by the end of the $10 \mathrm{~d}$ culture period. This might be a consequence of fluid retention in the LD group, since even at the end of the final load period LD discs still had a higher weight than at initial isolation. This indicates that discs did not revert back to the initial height even after a $10 \mathrm{~d}$ period with the LD regime. Therefore, the $\mathrm{LD}$ loading regime is insufficient to recapitulate in vivo load and recovery. As the loading was ended at the end of the second load cycle without time for the tissue to recover, it was expected that fluid would have been expelled and the weight to be lower compared to isolation. At HD loads, although tissue recovery was superior, cell viability was significantly reduced. This indicates that moderate-load exercising is more beneficial than high-load exercising for the overall disc homeostasis. For all load schemes, height-loss of the discs over the entire compression period increased, and height-gain also increased during recovery. Our analyses of dynamically cultured discs also revealed that all discs cultured under all loading schemes did not recover maximally even after $16 \mathrm{~h}$ of rest. These data, slightly differing from another biomechanics report (Walter et al., 2014), suggest that healthy and viable human lumbar IVDs recover at a similar slow speed, regardless of load magnitudes applied. Future experiments with longer rest periods following loading may elucidate maximal recovery times for IVDs.

Further comparing the present study with that of Walter et al. (2014), the effects of bony endplates seemingly has little effect on disc height recovery. The main advantage to retaining some thin layer of vertebral bone would be to ensure a flat surface. Retaining bone will also save time between harvest of tissue and placement of IVDs in culture medium. We have demonstrated here that bony endplates are not required for even-loading of IVDs when using flat, full coverage platens (Fig. 7). Potential disadvantages to retaining vertebral bone may be impairment of nutrient exchange over the culture duration. We have previously described the effects of vertebral bone (5 $\mathrm{mm}$ thick) on IVD cell viability in un-loaded culture, where bone retention significantly decreases cell viability (Gawri et al., 2011). While the study by Walter and colleagues (2014) (Walter et al., 2014) has shown that minimal bone retention maintains IVD cell viability in their loaded system. It is yet to be established, but it is likely, that the thickness of remaining bone significantly influences cell viability, where thicker bone $(5 \mathrm{~mm})$ impairs cell viability while retention of minimal bony endplates would preserve viability also in our system.

Physiological loading has been shown to promote IVD matrix maintenance by increasing expression of collagen type II, aggrecan and other matrix components (Chan et al., 2011; Gawri et al., 2014a; Walsh et al., 2004; Wuertz et al., 2009). Prominently healthy human lumbar discs, harvested from organ donors, were used for this study. As such, we do observe a small range of degenerative changes typically seen in the general population, such as water loss in the NP, fibrotic changes, fading intradiscal demarcation between nucleus and annulus and a minimal decrease in GAG concentration. However, loading of discs in this study had minimal effects on CHAD expression, fragmentation, newly synthesised collagen type II, or GAG loss. Future experimentation using this bioreactor set-up will focus on determining an "optimal range" of loading for human lumbar IVDs, which could potentially be used prophylactically for individuals exhibiting mild degeneration (Adams et al., 2015).

While some evidence was presented here for negative effects of high mechanical loading on IVD cell viability, there was no evidence for a loss of disc matrix integrity. This suggests that the HD loading scheme was below an acute injurious threshold, and it did not result in a radical catabolism as the one seen in our previous report where the same magnitude (1.2 MPa) was applied at a high speed to human IVDs (Alkhatib et al., 2014). Alternatively, a longer time period might be necessary to promote tissue degradation under the HD loading regime.

Numerous studies have shown the regenerative potential of cell-based therapies for repair and regeneration of degenerate discs (Illien-Junger et al., 2012; Kregar Velikonja et al., 2014; Leung et al., 2014), and autologous mesenchymal stem cell injections are currently being administered in clinical trials for disc repair (Orozco et al., 2011; Yoshikawa et al., 2010). We have demonstrated that when injected within a hydrogel carrier, isolated human NP 
cells will remain localised to the NP region, even after $14 \mathrm{~d}$ of moderate loading. This indicates that our ex vivo model for physiological organ culture of human IVDs provides a strong platform on which to test cell-based therapeutics for disc repair. Moreover, other biologic or drug therapeutics can be tested on this platform as well, making this an attractive model for pre-clinical studies of human disc repair and regeneration. Future studies will focus on the potential of stem cells and pre-differentiated stem cells to repair degenerate human IVDs under physiological loading and nutrient conditions.

\section{Acknowledgements}

This work was supported by the Canadian Institutes of Health Research (CIHR) grant CIHR MOP-119564 and AOSpine, SRN_2011_04_10498. We thank Marianna Peroglio for valuable discussions and advice regarding handling, cell seeding and RNA purification from the HA-pNIPAM hydrogel. DHR, JM, LB and RG, conducted experiments, analysed data, interpreted results and wrote the first draft of the manuscript. JAO was responsible for harvesting of Spines from organ donors. JAO, TS and PJR contributed to the design of the study, interpreted results and reviewed and revised manuscripts. DE provided HA-pNIPAM formulation, provided training on handling the hydrogel, performed experiments and reviewed and revised manuscript. LH designed the study, interpreted results, and wrote the manuscript. All authors approved of the final manuscript.

\section{Disclosures}

All authors disclose there are no conflicts of interest.

\section{References}

Adams MA, Lama P, Zehra U, Dolan P (2015) Why do some intervertebral discs degenerate, when others (in the same spine) do not? Clin Anat 28: 195-204.

Adams MA, Roughley PJ (2006) What is intervertebral disc degeneration, and what causes it? Spine (Phila Pa 1976) 31: 2151-2161.

Akhatib B, Onnerfjord P, Gawri R, Ouellet J, Jarzem P, Heinegard D, Mort J, Roughley P, Haglund L (2013) Chondroadherin fragmentation mediated by the protease htral distinguishes human intervertebral disc degeneration from normal aging. J Biol Chem 288: 19280-19287.

Alkhatib B, Rosenzweig DH, Krock E, Roughley PJ, Beckman L, Steffen T, Weber MH, Ouellet JA, Haglund L (2014) Acute mechanical injury of the human intervertebral disc: Link to degeneration and pain. Eur Cell Mater 28: 98-111.

Chan SC, Ferguson SJ, Gantenbein-Ritter B (2011) The effects of dynamic loading on the intervertebral disc. Eur Spine J 20: 1796-1812.

Chan SC, Walser J, Kappeli P, Shamsollahi MJ, Ferguson SJ, Gantenbein-Ritter B (2013) Region specific response of intervertebral disc cells to complex dynamic loading: An organ culture study using a dynamic torsioncompression bioreactor. PLoS One 8: e72489.

D'Este M, Alini M, Eglin D (2012) Single step synthesis and characterization of thermoresponsive hyaluronan hydrogels. Carbohydr Polym 90: 1378-1385.

Dabbs VM, Dabbs LG (1990) Correlation between disc height narrowing and low-back pain. Spine (Phila $\mathrm{Pa}$ 1976) 15: 1366-1369.

Dudli S, Ferguson SJ, Haschtmann D (2014) Severity and pattern of post-traumatic intervertebral disc degeneration depend on the type of injury. Spine J 14: 1256-1264.

Dudli S, Haschtmann D, Ferguson SJ (2012) Fracture of the vertebral endplates, but not equienergetic impact load, promotes disc degeneration in vitro. J Orthop Res 30: 809-816.

Gantenbein B, Illien-Junger S, Chan SC, Walser J, Haglund L, Ferguson SJ, Iatridis JC, Grad S (2015) Organ culture bioreactors - platforms to study human intervertebral disc degeneration and regenerative therapy. Curr Stem Cell Res Ther 10: 339-352.

Gawri R, Moir J, Ouellet J, Beckman L, Steffen T, Roughley P, Haglund L (2014a) Physiological loading can restore the proteoglycan content in a model of early ivd degeneration. PLoS One 9: e101233.

Gawri R, Mwale F, Ouellet J, Roughley PJ, Steffen T, Antoniou J, Haglund L (2011) Development of an organ culture system for long-term survival of the intact human intervertebral disc. Spine (Phila Pa 1976) 36: 1835-1842.

Gawri R, Rosenzweig DH, Krock E, Ouellet JA, Stone LS, Quinn TM, Haglund L (2014b) High mechanical strain of primary intervertebral disc cells promotes secretion of inflammatory factors associated with disc degeneration and pain. Arthritis Res Ther 16: R21.

Haglund L, Moir J, Beckman L, Mulligan KR, Jim B, Ouellet JA, Roughley P, Steffen T (2011) Development of a bioreactor for axially loaded intervertebral disc organ culture. Tissue Eng Part C Methods 17: 1011-1019.

Holm S, Maroudas A, Urban JP, Selstam G, Nachemson A (1981) Nutrition of the intervertebral disc: Solute transport and metabolism. Connect Tissue Res 8: 101-119.

Humzah MD, Soames RW (1988) Human intervertebral disc: structure and function. Anat Rec 220: 337-356.

Illien-Junger S, Gantenbein-Ritter B, Grad S, Lezuo P, Ferguson SJ, Alini M, Ito K (2010) The combined effects of limited nutrition and high-frequency loading on intervertebral discs with endplates. Spine (Phila Pa 1976) 35: 1744-1752.

Illien-Junger S, Pattappa G, Peroglio M, Benneker LM, Stoddart MJ, Sakai D, Mochida J, Grad S, Alini M (2012) Homing of mesenchymal stem cells in induced degenerative intervertebral discs in a whole organ culture system. Spine (Phila Pa 1976) 37: 1865-1873.

Jim B, Steffen T, Moir J, Roughley P, Haglund L (2011) Development of an intact intervertebral disc organ culture system in which degeneration can be induced as a prelude to studying repair potential. Eur Spine J 20: 1244-1254.

Junger S, Gantenbein-Ritter B, Lezuo P, Alini M, Ferguson SJ, Ito K (2009) Effect of limited nutrition on in situ intervertebral disc cells under simulated-physiological loading. Spine (Phila Pa 1976) 34: 1264-1271. 
Katz JN (2006) Lumbar disc disorders and low-back pain: Socioeconomic factors and consequences. J Bone Joint Surg Am 88 Suppl 2: 21-24.

Kregar Velikonja N, Urban J, Frohlich M, NeidlingerWilke C, Kletsas D, Potocar U, Turner S, Roberts S (2014) Cell sources for nucleus pulposus regeneration. Eur Spine J 23 Suppl 3: S364-374.

Krock E, Rosenzweig DH, Haglund L (2015) The inflammatory milieu of the degenerate disc: Is mesenchymal stem cell-based therapy for intervertebral disc repair a feasible approach? Curr Stem Cell Res Ther 10: $317-328$.

Leung VY, Aladin DM, Lv F, Tam V, Sun Y, Lau RY, Hung SC, Ngan AH, Tang B, Lim CT, Wu EX, Luk KD, Lu WW, Masuda K, Chan D, Cheung KM (2014) Mesenchymal stem cells reduce intervertebral disc fibrosis and facilitate repair. Stem Cells 32: 2164-2177.

Marchand F, Ahmed AM (1990) Investigation of the laminate structure of lumbar disc anulus fibrosus. Spine (Phila Pa 1976) 15: 402-410.

McNally DS, Adams MA (1992) Internal intervertebral disc mechanics as revealed by stress profilometry. Spine (Phila Pa 1976) 17: 66-73.

Mort JS, Roughley PJ (2007) Measurement of glycosaminoglycan release from cartilage explants. Methods Mol Med 135: 201-209.

Mulligan KR, Ferland CE, Gawri R, Borthakur A, Haglund L, Ouellet JA (2015) Axial t1rho mri as a diagnostic imaging modality to quantify proteoglycan concentration in degenerative disc disease. Eur Spine J 24: 2395-2401.

Mwale F, Wang HT, Roughley P, Antoniou J, Haglund L (2014) Link $n$ and mesenchymal stem cells can induce regeneration of the early degenerate intervertebral disc. Tissue Eng Part A 20: 2942-2949.

Nachemson A (1960) Lumbar intradiscal pressure. Experimental studies on post-mortem material. Acta Orthop Scand Suppl 43: 1-104.

Orozco L, Soler R, Morera C, Alberca M, Sanchez A, Garcia-Sancho J (2011) Intervertebral disc repair by autologous mesenchymal bone marrow cells: A pilot study. Transplantation 92: 822-828.

Parolin M, Gawri R, Mwale F, Steffen T, Roughley P, Antoniou J, Jarzem P, Haglund L, Ouellet J (2010) Development of a whole disc organ culture system to study human intervertebral disc. Evid Based Spine Care J 1: 67-68.

Pattappa G, Peroglio M, Sakai D, Mochida J, Benneker LM, Alini M, Grad S (2014) Ccl5/rantes is a key chemoattractant released by degenerative intervertebral discs in organ culture. Eur Cell Mater 27: 124-136.

Paul CP, Schoorl T, Zuiderbaan HA, Zandieh Doulabi $B$, van der Veen AJ, van de Ven PM, Smit TH, van Royen BJ, Helder MN, Mullender MG (2013) Dynamic and static overloading induce early degenerative processes in caprine lumbar intervertebral discs. PLoS One 8: e62411.

Paul CP, Zuiderbaan HA, Zandieh Doulabi B, van der Veen AJ, van de Ven PM, Smit TH, Helder MN, van Royen BJ, Mullender MG (2012) Simulated-physiological loading conditions preserve biological and mechanical properties of caprine lumbar intervertebral discs in ex vivo culture. PLoS One 7: e33147.

Peroglio M, Eglin D, Benneker LM, Alini M, Grad S (2013) Thermoreversible hyaluronan-based hydrogel supports in vitro and ex vivo disc-like differentiation of human mesenchymal stem cells. Spine J 13: 1627-1639.

Peroglio M, Grad S, Mortisen D, Sprecher CM, Illien-Junger S, Alini M, Eglin D (2012) Injectable thermoreversible hyaluronan-based hydrogels for nucleus pulposus cell encapsulation. Eur Spine J 21 Suppl 6: S839849.

Selinummi J, Seppala J, Yli-Harja O, Puhakka JA (2005) Software for quantification of labeled bacteria from digital microscope images by automated image analysis. Biotechniques 39: 859-863.

Walsh AJ, Lotz JC (2004) Biological response of the intervertebral disc to dynamic loading. J Biomech 37 : 329-337.

Walter BA, Illien-Junger S, Nasser PR, Hecht AC, Iatridis JC (2014) Development and validation of a bioreactor system for dynamic loading and mechanical characterization of whole human intervertebral discs in organ culture. J Biomech 47: 2095-2101.

Walter BA, Korecki CL, Purmessur D, Roughley PJ, Michalek AJ, Iatridis JC (2011) Complex loading affects intervertebral disc mechanics and biology. Osteoarthritis Cartilage 19: 1011-1018.

Wilke HJ, Rohlmann A, Neller S, Graichen F, Claes L, Bergmann G (2003) Issls prize winner: A novel approach to determine trunk muscle forces during flexion and extension: A comparison of data from an in vitro experiment and in vivo measurements. Spine (Phila $\mathrm{Pa}$ 1976) 28: 2585-2593.

Wuertz K, Godburn K, MacLean JJ, Barbir A, Donnelly JS, Roughley PJ, Alini M, Iatridis JC (2009) In vivo remodeling of intervertebral discs in response to short- and long-term dynamic compression. J Orthop Res 27: 12351242.

Yoshikawa T, Ueda Y, Miyazaki K, Koizumi M, Takakura Y (2010) Disc regeneration therapy using marrow mesenchymal cell transplantation: A report of two case studies. Spine (Phila Pa 1976) 35: E475-480.

\section{Discussion with Reviewers}

Reviewer II: What would be the effect of the free swelling period prior to loading, also given the data by van Dijk et al. (2011, Additional Reference) suggesting that free swelling alters cell behaviour and induces matrix degradation?

Authors: The "free swelling" period in question by the Reviewer may indeed have an effect on cell behaviour and potential matrix degradation. However, in the study by van Dijk et al., bovine NP tissue explants were removed from the $\mathrm{AF}$ and the cartilage endplates, allowing maximal uptake of liquid, and maximal induced strain on the tissue/ cells. This in fact, may be the reason for the observed phenotypic changes (as the authors themselves point out). Indeed, we and others have observed overload- and excessive strain-induced phenotypic changes associated 
with matrix disruption and degeneration (Gawri et al., 2014; Chan et al, 2013; Walter et al., 2011). In the present study, the initial unloaded culture period is not the same as "free swelling" since the IVDs are contained, with the $\mathrm{AF}$, surrounding the NP, and the whole disc enclosed in the cartilage endplates. The system used here is a contained system; limiting the swelling to around $20 \%$. In contrast, swelling can be up to $100 \%$ when the cartilaginous endplates are removed (we have 2 publications on this). Ultimately, all of our data indicate that under these conditions, cell phenotype remains unaltered and matrix degradation is not increased above the basal activity.

\section{Additional Reference}

van Dijk B, Potier E, Ito K (2011) Culturing bovine nucleus pulposus explants by balancing medium osmolarity. Tissue Eng Part C Methods 17: 1089-1096.

Editor's Note: Scientific Editor in charge of the paper: Brian Johnstone. 